\title{
Araştırma-Geliştirme Faaliyetlerinin Firma Karlılığı Üzerine Etkisi: BİST 100 Endeksinde Bir Uygulama
}

\section{The effect of research \& development activities on the firms profitability: An application in BIST 100 index}

\author{
Emin ÇAĞLAK ${ }^{1}$ \\ Hafize MEDER ÇAKIR ${ }^{2 a}$
}

\author{
${ }^{1}$ Afyon Kocatepe Üniversitesi, Başmakçı MYO, Afyon. ecaglak@aku.edu.tr \\ ${ }^{2}$ Pamukkale Üniversitesi, İktisadi ve İdari Bilimler Fakültesi, Denizli. hmeder@pau.edu.tr \\ a Yazışlan yazar/Corresponding author
}

\begin{abstract}
Özet
Bilim ve teknolojideki hızl gelişmeler, firmaları da derinden etkiler hale gelmiştir. Özellikle bilim ve teknolojinin firmalar arasinda rekabette üstünlük aracı haline gelmesi, firmalarn bilim ve teknolojiye yaptığ yatırimları artırmaktadır. Bu yatırimlarin firma karna etkisi hem firmalar için, hem de akademik camia için merak konusudur. Bu çalı̧̧mada 1999-2017 dönemi için Bist-100'de yer alan firmalarm Ar-Ge harcamalariyla firma karlilığı arasındaki ilişkiyi Pedroni eşbütünleșme testi ile, eşbütünleşme ilişkisinin katsayıları ise DOLS ve FMOLS eşbütünleşme testleri ile analiz edilmiştir. Yapilan analiz sonucunda firmalarn Ar\&Ge harcamaları ile Kar (FAVÖK) rakamlarının uzun dönem eşbütünleşik olduğu, yani uzun dönemde birlikte hareket ettikleri ve hareket yönünün pozitif yönlü olduğu ortaya çıkmıştır.
\end{abstract}

Anahtar kelimeler: Ar-Ge, Kar, Pedroni Eşbütünleşme, DOLS, FMOLS

JEL kodlart: O10, O11, O30,O40.

\begin{abstract}
Rapid developments in science and technology have deeply affected firms. In particular, the fact that science and technology become a means of superior advantage among companies increases the investments made by companies in science and technology. The impact of these investments on the firm is a matter of curiosity for both companies and the academic community. In this study, the relationship between the RED expenditures and the profitability of firms in Bist 100 between 1999-2017 was analyzed by Pedroni cointegration test. Coefficient of cointegration relation was also analyzed by DOLS and FMOLS cointegration tests. As a result of the analysis, it has been found that companies' RED expenditures and profit (EBIDTA) figures are long term cointegrated. That is to say they move together and positive in the long term.
\end{abstract}

Keywords: RED, EBIDTA, Pedroni Cointegration, DOLS, FMOLS

JEL codes: O10, O11, O30,O40. 


\section{GİRIŞ}

Bilimsel ve teknik bilgi birikimini artırmak amacıyla, sistematik bir temele dayalı olarak yürütülen, yenilikçi çaba ve bu bilgi birikiminin yeni uygulamalarda kullanıldığı Araştırma ve Geliştirme (Ar-Ge) faaliyetleri, ülkeler ve firmaların istikrarlı bir ekonomik büyüme yakalayabilmeleri ve refah artışını mümkün kılabilmeleri için büyük önem arz etmektedir. Daha az kaynakla, daha fazla katma değer yaratma çabası, gerek firmaların, gerekse devletlerin araştırma-geliştirme (Ar-Ge) ve inovasyon faaliyetlerine doğru yöneldiklerini göstermektedir. Ülkelerin gelişmişlik düzeyleri ile sahip oldukları teknoloji arasında paralellik söz konusudur. Teknolojik gelişme ise, Ar-Ge harcamalarının neticesi olarak karşımıza çıkmaktadır.

Romer (1990), Grossman ve Helpman (1991) ve Aghion ve Howitt (1992) tarafından yapılan çalışmalarda, Ar-Ge harcamaları ile oluşturulan ekonomik büyüme modellerinde, firmaların Ar-Ge harcamaları sayesinde hedefledikleri maksimum karlılık, teknolojik gelişme ve sürekli büyümeyi gerçekleştirdikleri tespit edilmiştir. Ayrıca, yenilik faaliyetleri ile elde edilen patentler sayesinde de hem rekabet üstünlügü sağlanacağı, hem de piyasada monopol bir etki oluşturacağı öngörülmüştür. Yeni patentler yoluyla elde edilen kar artışı Ar-Ge'nin birim başına getirisini de yükseltmektedir. Bunun neticesi de yeni sermaye malı üretimine teşvik oluşturmaktadır.

Bu çalışmanın amacı, 1999-2017 dönemi için BİST-100'de yer alan firmaların Ar-Ge harcamalarıyla firma karlılığı arasındaki ilişkiyi Pedroni eşbütünleşme testi ile, eşbütünleşme ilişkisinin katsayılarını ise yine 2000-2001'de Pedroni tarafından geliştirilen DOLS ve FMOLS eşbütünleşme testleri ile analiz etmektir. Çalışmada ilk olarak Ar-Ge ve Karlılık ile ilgili kavramsal çerçeve oluşturululmuş, daha sonra Ar-Ge harcamaları ve karlılık ile literatür çalışmalarına yer verilmiş ve son olarak BİST-100 endeksinde ilgili dönem aralığında Ar-Ge harcamaları süreklilik arzeden firmaların Ar-Ge harcamaları ile karlılıkları arasındaki ilişki test edilmiştir.

\section{KAVRAMSAL ÇERÇEVE}

OECD tarafından Ar-Ge, toplum, kültür ve beşeri konular da dahil olmak üzere bilgi dağarcığını artırmak ve bu bilgileri yeni uygulamalarda kullanmak amacıyla yürütülen bütün çalışmalar olarak tanımlanmaktadır.

Buna göre Ar-Ge aşağıdaki üç ana faaliyeti kapsamaktadıra:

- Temel araştırma (basic research); belirli bir uygulama veya kullanım gözetilmeyerek kuramsal veya deneysel çalışmalarla olguların ve gözlemlenebilir durumların altında yatan etkenlere ilişkin yeni bilgi edinilmesine yönelik çalışmalardır.

- Uygulamalı araştırma (applied research); belirli bir amaca yönelik olarak tarım, sağlık, endüstriyel kimya gibi alanlarda yeni bilgi elde etmek amacıyla yürütülen faaliyetlerdir.

Deneysel geliştirme (experimental development); araştırmadan ve/veya pratik deneyimden edinilmiş olan bilgilerin kullanılarak yeni süreçlerin, sistemlerin ve hizmetlerin oluşturulması veya halen üretilmiş veya oluşturulmuş olanların iyileştirmesi amacıyla yeni materyaller, ürünler veya süreçler geliştirmeye yönelik çalışmalardır.

\footnotetext{
${ }^{a}$ http://stats.oecd.org/glossary/detail.asp?ID=3111
} 


\subsection{Dünyada ve Türkiye'de Ar-Ge Yoğunluğu}

Bir ülkede yapılan Ar-Ge harcamalarının Gayri Safi Yurt İçi Hasıla (GSYİH) rakamlarına bölünmesiyle elde edilen gösterge o ülkenin Ar-Ge yoğunluğunu ifade etmektedir. Bu gösterge, ülkenin milli gelirinden Ar-Ge'ye ne kadar pay ayrıldı̆̆ını gösterir (Adaçay, 2007: 188).

Ülkelerin araştırma ve geliştirme faaliyetleri için, yapmış oldukları harcamaların yüzdelerine bakıldığında, OECD ortalamasının gayri safi yurtiçi hasılanın \%2.40'üne karşılık geldiği görülmektedir. OECD ülkeleri içinde İsrail en fazla Ar-Ge harcaması yapan ülke olarak dikkati çekmektedir. Türkiye'nin gayri safi yurtiçi hasılasından Ar-Ge için yaptığ harcamaya bakıldığında ise, 0.95 'lik bir oran ile OECD ortalamasının çok altında kaldığ görülmektedir (Şekil 1). Bu açıdan ülkemizde gelişmişlik düzeyini artırabilmek ve küresel alanda rekabet edebilmek için yeni ürün ve teknolojin geliştirilmesi şarttır.

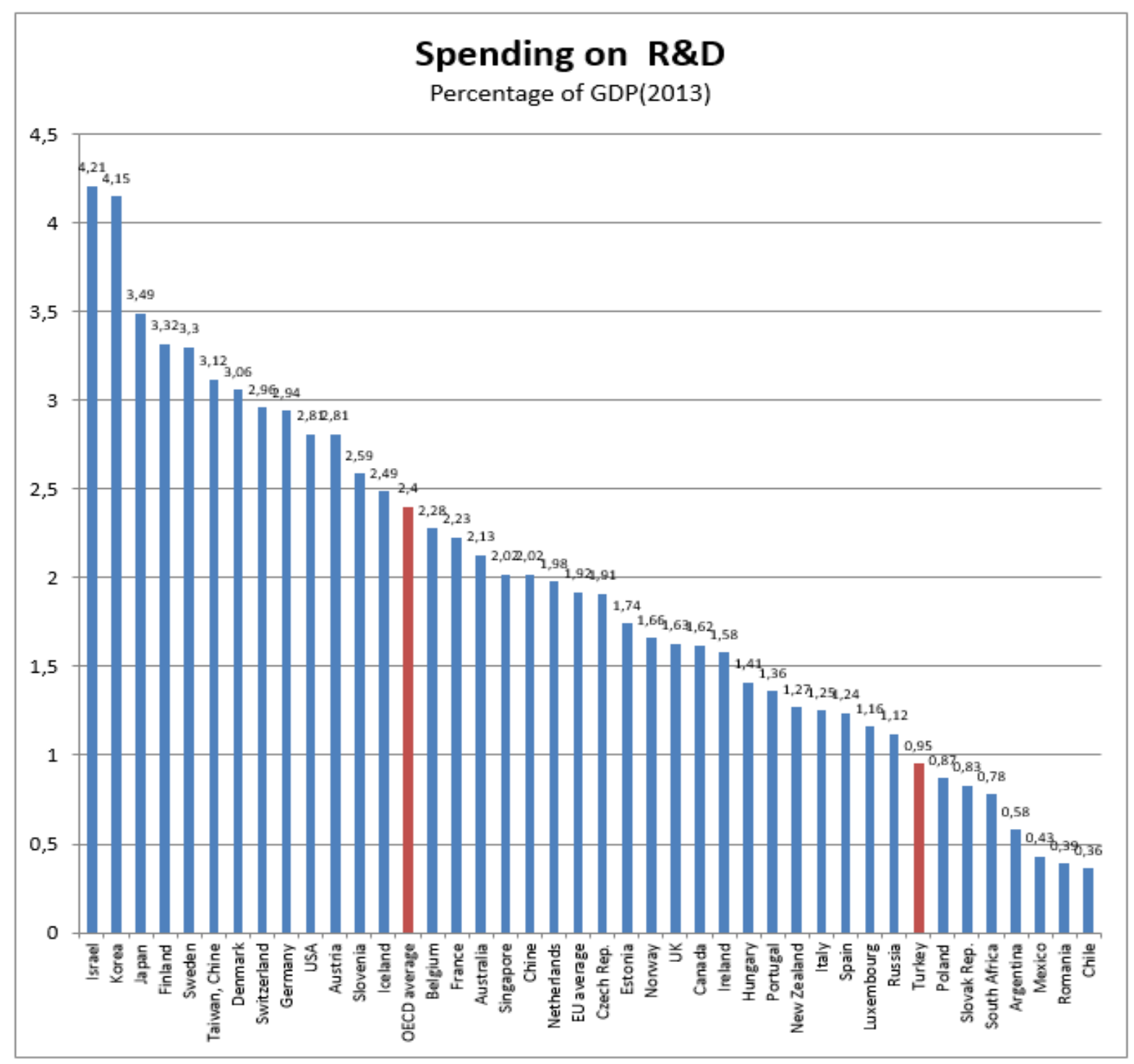

Şekil 1. Ülkelerin Ar-Ge Harcama Yüzdeleri (Kaynak: OECD ${ }^{\mathrm{b}}$ )

\footnotetext{
${ }^{\mathrm{b}}$ https://data.oecd.org/rd/gross-domestic-spending-on-r-d.htm\#indicator-chart
} 
Ar-Ge yoğunluğu, gerek devlet gerekse özel sektör için bilim ve teknoloji açısından rekabette üstünlüğün bir göstergesidir. Ar-Ge harcamalarının GSYİH içindeki payının yıllara göre gelişimine bakıldığında (Tablo 1) AB ülkeleri, ABD ve Japonya'da olduğu gibi ülkemizde de istikrarlı bir artışın olduğu gözlemlenmektedir. 1998 yılı baz alındığında, 2015 yılı itibariyle Ar-Ge harcamalarındaki artış oranı AB'nde \%14, ABD'de \%8, Japonya'da \%10 düzeyinde iken, Türkiye'de bu oran \%138 düzeyinde gerçekleşmiştir. Türkiye'de Ar-Ge yüzdesinin diğerlerine kıyasla çok düşük olduğu görülmekle birlikte, yıllar itibariyle düzenli artış göstermesinin yanında, oransal olarak da daha yüksek bir artış göstermesi ülkemiz açısından umut vericidir.

Tablo 1. Yillar İtibariyle Ar-Ge'nin GSYİH'ya Oranı (\%)

\begin{tabular}{ccccc}
\hline Yil & AB $^{*}$ & ABD & Japonya & Türkiye \\
\hline 1998 & 1,79 & 2,58 & 3,00 & 0,37 \\
\hline 1999 & 1,84 & 2,63 & 3,02 & 0,47 \\
\hline 2000 & 1,86 & 2,69 & 3,04 & 0,48 \\
\hline 2001 & 1,87 & 2,71 & 3,12 & 0,53 \\
\hline 2002 & 1,88 & 2,60 & 3,17 & 0,48 \\
\hline 2003 & 1,87 & 2,60 & 0,52 \\
\hline 2004 & 1,83 & 2,53 & 0,59 \\
\hline 2005 & 1,83 & 2,56 & 3,17 & 0,60 \\
\hline 2006 & 1,76 & 2,59 & 0,72 \\
\hline 2007 & 1,77 & 2,66 & 3,32 & 0,73 \\
\hline 2008 & 1,84 & 2,79 & 3,40 & 0,85 \\
\hline 2009 & 1,93 & 2,82 & 3,45 & 0,84 \\
\hline 2010 & 1,93 & 2,74 & 3,36 & 0,80 \\
\hline 2011 & 1,97 & 2,77 & 3,14 & 0,83 \\
\hline 2012 & 2,01 & 2,70 & 3,24 & 0,82 \\
\hline 2013 & 2,02 & 2,73 & 3,21 & 0,86 \\
\hline 2014 & 2,03 & 2,75 & 3,32 & 0,88 \\
\hline 2015 & 2,04 & 2,79 & 3,40 & - \\
\hline 2016 & 2,03 & - & 3,29 & - \\
\hline
\end{tabular}

Kaynak: EUROSTAT, 2015; GSYİH göre Ar\&Ge Harcamaları OECD, 2015.

* 27 birlik üyesi

Türkiye'deki sektörlerin yıllar itibariyle Ar-Ge için yapmış oldukları harcamalar Şekil 2.2' de yer almaktadır. Şekil 2 incelendiğinde Bilgi İletişim Teknolojileri, Otomotiv imalatı ve Mimarlık sektörlerinin gerek harcama hacmi olarak, gerekse artış oranı olarak diğerlerinden ayrıştıkları görülmektedir. Bu sektörlerin teknoloji ağırlıklı olması ve teknolojik yeniliklerin önemli rekabet gücü sağlaması nedeniyle bu sektörlerdeki firmalar Ar-Ge faaliyetlerine daha fazla önem vermektedir. 


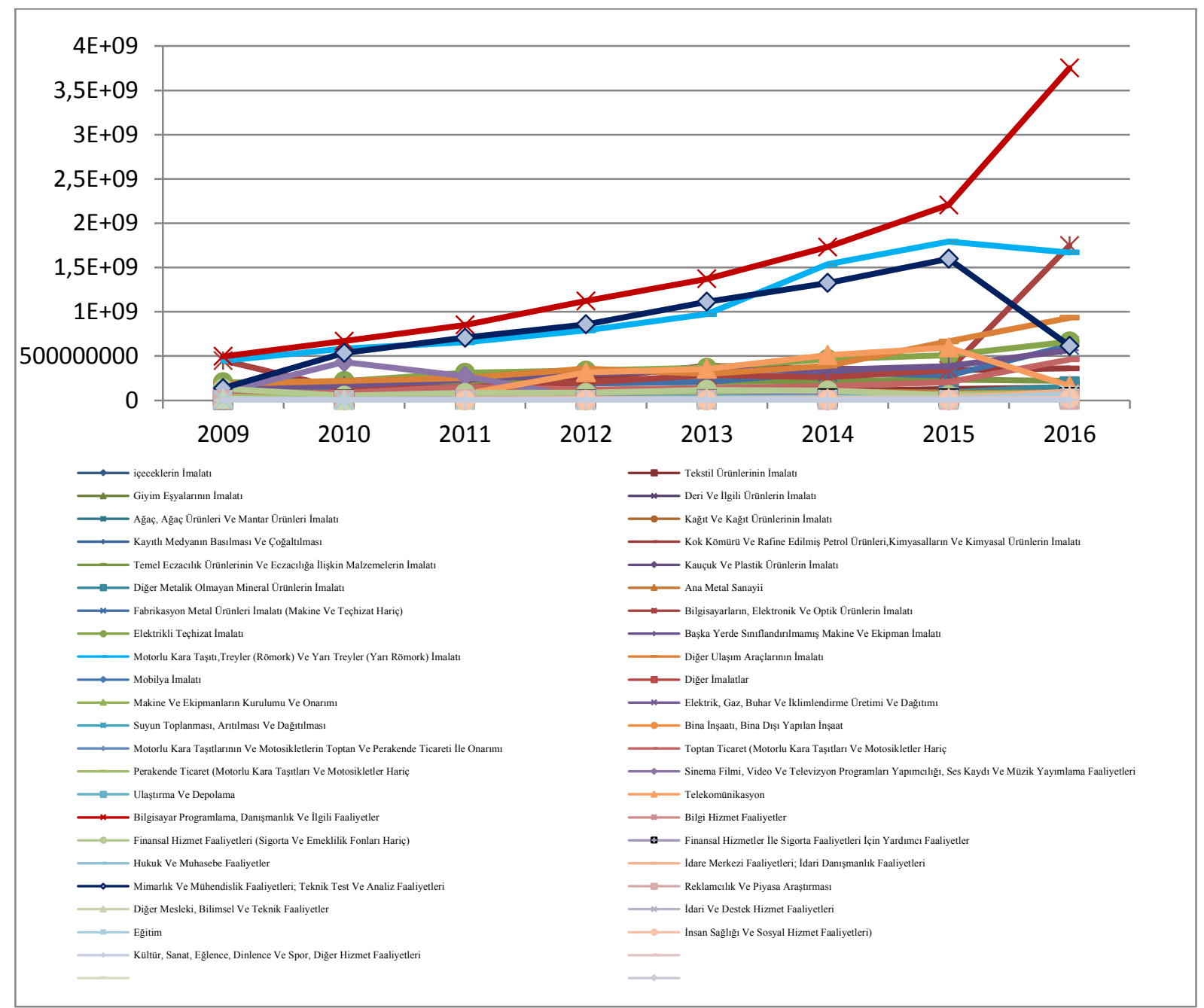

Şekil 2. Türkiye' de Ar-Ge Harcamalarının Sektörel Dağılımı (TL) - (Kaynak: TUİK)

\section{VERI SETİ VE EKONOMETRIKK MODEL}

Yapılan panel veri analizi BİST-100 endeksinde yer alan firmaları kapsamaktadır. Firmaların 1999-2017 dönemleri arasındaki gelir tablolarında yer alan Araştırma ve Geliştirme Giderleri ile Faiz Amortisman ve Vergi Öncesi Kar (FAVÖK) rakamlarından oluşan veri seti Bloomberg veri tabanından elde edilmiştir. Endekste yer alan firmaların sadece 29 tanesinin düzenli olarak Araştırma ve Geliştirmeye yönelik harcama yaptığı̆, büyük bir kısmının ise her yıl düzenli olarak Ar-Ge harcaması yapmadığı tespit edilmiştir. Bu durum araştırma sonuçlarında sapmalara neden olabileceği için veri seti, BISTT-100 endeksinin tamamı yerine, söz konusu dönemler içinde düzenli olarak Ar-Ge harcaması yapan 29 firma ile sınırlandırılmıştır. Veri setindeki firmaların sektörel dağılımları incelendiğinde, en yüksek paya sahip sektörlerin \%17'lik paylar ile Otomotiv ve Beyaz Eşya Mobilya, \%14'lük payla Gıda, \%10'arlık paylarla Enerji, İlaç-Kimya ve Cam-Ambalaj sektörleri olduğu, görülmektedir. Bu dağılımın yaklaşık \%70'lik kısmı, Ar-Ge yoğun sektörlerdeki firmalardan oluşmaktadır (Şekil 3). 


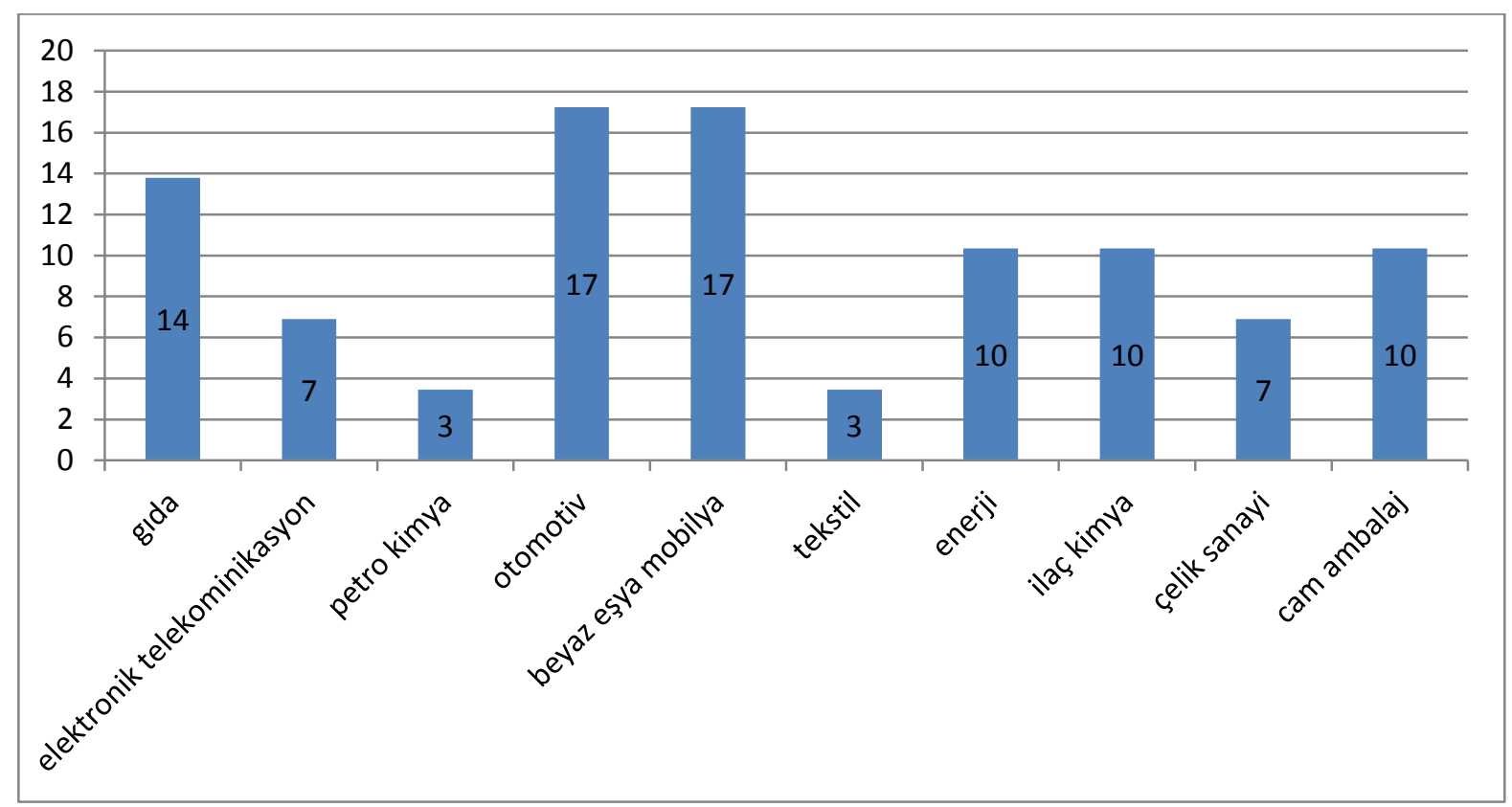

Şekil 3. BİST-100'deki Ar-Ge Harcaması Yapan Firmaların Sektörel Dağılımı

Çalışmaya konu Ar-Ge göstergesi, dönem içinde kar zarar hesabında aktifleştirilmiş Ar-Ge harcamalarını içerirken, kar rakamı olarak Faiz, Amortisman ve Vergi Öncesi Kar (FAVÖK) rakamları kullanılmıştır. Verilerin analizi için logaritmik farkları alınmıştır.

Çalışmada kullanılan ekonometrik model (1) nolu eşitlikte gösterilmektedir:

$d \operatorname{Kar}_{i t}=\alpha_{i t}+\beta d R \& D_{i t}+u_{i t}$

$i, i=1,2, \ldots . . N$ ile kesiti $t$ ise $t=1,2, \ldots \ldots . T$ ile zaman periyodunu temsil etmektedir. $\alpha$, veri miktarını (scalar) gözlem sayısını; $\beta, \mathrm{K} \times 1$ 'i göstermektedir, it $x$, $\mathrm{K}$ açılayıcı değişkenleri ile ilgili it'ninci gözlem sayısıdır. İlk firma ile ilgili $T$ gözlemi, ikinci firma ile ilgili $T$ gözlemini takip etmekte ve N'inci firmaya kadar bu şekilde devam etmektedir.

Hata terimi bileşenleri aşağıdaki şekilde ifade edilebilir (Baltagi, 2011: 306):

$u_{i t}=\mu_{i}+v_{i t}$

$\mu_{i}$, kesitin belli bileşenlerini, $v_{i t}$ ise geri kalan etkileri göstermektedir (Baltagi, 2011:306). Yani burada zamana bağlı olmayan ancak kesitten kesite farklılık gösteren $\mu_{i}$ bireysel etki olarak isimlendirilirken $v_{i t}$ 'nin hem zamana, hem de kesite göre değişim gösterdiği varsayılmaktadır. Buna göre $\mu_{i}$ gözlemlenemeyen kesit etkisini göstermekte, $v_{i t}$ ise stokastik hata terimini sembolize etmektedir (Gülmez ve Yardımcıoğlu, 2012: 342).

\section{LİTERATÜR ÖZETI}

Araştırma ve geliştirme için yapılan harcamaların, işletmelere, dolayısıyla ülkelere çeşitli açılardan etkisini inceleyen ulusal ve uluslararası birçok araştırma yapılmıştır. Bu çalışmalardan bazıları, daha kolay anlaşılabilmesi için aşağıdaki özet tabloyla (Tablo 2) sunulmuştur. 
Tablo 2. Ar-ge Harcamalarının Etkisini Araştıran Çalışma Örnekleri

\begin{tabular}{|c|c|c|c|c|c|}
\hline Künye & Ülke & Periyod & $\begin{array}{c}\text { Kullanılan } \\
\text { Teknik }\end{array}$ & Veriler & Sonuç \\
\hline $\begin{array}{l}\text { Graham } \\
(1989)\end{array}$ & $\mathrm{ABD}$ & 1976-1985 & Korelasyon & $\begin{array}{l}\text { Satışlar, } \\
\text { Karlılık, } \\
\text { Ar-Ge } \\
\text { Harcamaları }\end{array}$ & $\begin{array}{l}\text { Endüstrilerin Ar-Ge yoğunluğu ve kar büyümesi } \\
\text { arasındaki ilişkinin bilgisayar, kimya, sanayi } \\
\text { şirketleri dışındaki şirketlerde genellikle önemsiz } \\
\text { olduğu gözlemlenmiştir. Yapıllan analiz Ar-Ge } \\
\text { faaliyetinin karlılıkta önemli bir büyümeye yol açtığı } \\
\text { hipotezine çok az destek sağlamaktadır. }\end{array}$ \\
\hline $\begin{array}{l}\text { Hu ve } \\
\text { Jefferson } \\
(2004)\end{array}$ & Çin & 1991-1997 & $\begin{array}{l}\text { Panel } \\
\text { Nedensellik }\end{array}$ & $\begin{array}{l}\text { Ar-Ge } \\
\text { Harcamaları, } \\
\text { Firma Büyüklüğ̈̈, } \\
\text { Satıs rakamları, } \\
\text { Kar } \\
\end{array}$ & $\begin{array}{l}\text { Ar-Ge harcamasının, firma büyüklüğü ile orantılı } \\
\text { olarak daha az artığı, aynı zamanda nakit akışı ile } \\
\text { ilgisi olmadığı sonucuna varılmıştır.. }\end{array}$ \\
\hline $\begin{array}{l}\text { Altın ve Kaya } \\
\text { (2009) }\end{array}$ & Türkiye & $1990-2005$ & $\begin{array}{l}\text { VEC (Vector } \\
\text { Error } \\
\text { Correction) } \\
\text { modeli }\end{array}$ & $\begin{array}{l}\text { AR-GE } \\
\text { Harcamaları, } \\
\text { GSYH }\end{array}$ & $\begin{array}{l}\text { Ar-Ge rakamları ile ekonomik büyüme rakamları } \\
\text { arasında kısa dönemli ilişkinin varlığı tespit } \\
\text { edilemezken, uzun dönemde iki değişken arasında } \\
\text { Ar-Ge'den ekonomik büyümeye doğru tek yönlü } \\
\text { ilişki tespit edilmiştir. }\end{array}$ \\
\hline $\begin{array}{l}\text { Korkmaz } \\
(2010)\end{array}$ & Türkiye & $1990-2008$ & $\begin{array}{l}\text { Johansen coin } \\
\text { tegration test }\end{array}$ & $\begin{array}{l}\text { GSYİH, } \\
\text { GSYİH Deflatörü, } \\
\text { Ar-Ge } \\
\text { Harcamaları }\end{array}$ & $\begin{array}{l}\text { Ar-Ge harcamaları ile ekonomik büyüme rakamları } \\
\text { arasında minimum bir tane Eşbütünleşik vektörün } \\
\text { varlığı tespit edilmiş, dolayısıyla GSYİH ile Ar-Ge } \\
\text { harcamaları arasında anlamlı ve pozitif ilişkinin } \\
\text { olduğu sonucuna varılmıştır. }\end{array}$ \\
\hline $\begin{array}{l}\text { Francesco ve } \\
\text { Mario (2010) }\end{array}$ & $\begin{array}{l}\text { Almanya, } \\
\text { Fransa, } \\
\text { İtalya, } \\
\text { Norveç, } \\
\text { Hollanda, } \\
\text { Portekiz, } \\
\text { İspanya, } \\
\text { İngiltere }\end{array}$ & 1994-2006 & $\begin{array}{l}\text { Panel } \\
\text { Cointegration }\end{array}$ & $\begin{array}{l}\text { Ar-Ge } \\
\text { Harcamaları, Satı̧̧ } \\
\text { Rakamları, } \\
\text { Karlılık }\end{array}$ & $\begin{array}{l}\text { Çalışmada Ar-Ge, yenilik ve karlılık ilişkilerini } \\
\text { anlamak için bir model oluşturulmuştur. Model } \\
\text { Avrupa sanayilerinde Ar-Ge, yenilik ve kar } \\
\text { dinamiklerinin etkili bir şekilde hesaplandı̆ğın } \\
\text { göstermektedir. Çalışmaya göre, endüstrilerin } \\
\text { yenilikçi ve ekonomik sonuçları çeşitli kaynakların ve } \\
\text { stratejilerin sonucudur. Teknolojik ve maliyet } \\
\text { rekabetçiliğinin farklı stratejileri farklı girdileri } \\
\text { kullanır ve pazarlamadaki farklılıkları kullanarak bir } \\
\text { ülkenin endüstrilerini yönlendirir. }\end{array}$ \\
\hline $\begin{array}{l}\text { Gülmez ve } \\
\text { Yardımcioğlu } \\
\text { (2012) }\end{array}$ & $\begin{array}{l}\text { OECD } \\
\text { Ülkeleri }\end{array}$ & $1996-2011$ & $\begin{array}{l}\text { Yatay Kesit } \\
\text { Bağımlılı̆̆ } \\
\text { Panel } \\
\text { Eşbütünleşme } \\
\text {, }\end{array}$ & $\begin{array}{l}\text { Ar-Ge } \\
\text { Harcamaları, } \\
\text { Sabit sermaye } \\
\text { oluşumu, } \\
\text { İşgücü artış oranı }\end{array}$ & $\begin{array}{l}\text { Ar-Ge harcamaları, sabit sermaye oluşumu ve iş gücü } \\
\text { artış oranı ile ekonomik büyüme değerleri arasında } \\
\text { pozitif ilişki tespit edilmiştir. Ar-Ge'deki bir birimlik } \\
\text { artışın ekonomik büyümeye } 3.4 \text { birim etki yaptığı, } \\
\text { diğer değişkenlerde ise bir birimlik artışı } 0,20 \text { ve } \\
0,21 \text { birimlik artı̧̧a sebep olduğu ortaya çıarılmıştır. }\end{array}$ \\
\hline $\begin{array}{l}\text { Gülmez ve } \\
\text { Yardımcioğlu } \\
\text { (2012) }\end{array}$ & $\begin{array}{l}\text { OECD } \\
\text { ülkeleri }\end{array}$ & $1990-2010$ & $\begin{array}{l}\text { Panel } \\
\text { eşbütünleşme, } \\
\text { Panel } \\
\text { Nedensellik }\end{array}$ & $\begin{array}{l}\text { kişi başı Ar-Ge } \\
\text { harcamaları, } \\
\text { kişi başı GSYİH } \\
\text { harcamaları }\end{array}$ & $\begin{array}{l}\text { Ar-Ge rakamları ile GSYİH arasında uzun dönemde } \\
\text { eşbütünleşme ilişkisinin varlığı Pedroni ve Kao } \\
\text { testleri ile ortaya konulmusstur. Değişkenler } \\
\text { arasındaki nedensellik ilişkisinin yönü ise çift taraflı } \\
\text { olarak tespit edilmiştir. }\end{array}$ \\
\hline $\begin{array}{l}\text { Ünal ve } \\
\text { Seçilmiş } \\
\text { (2013) }\end{array}$ & $\begin{array}{l}\text { AB } \\
\text { Ülkeleri, } \\
\text { ABD, } \\
\text { Japonya, } \\
\text { Türkiye } \\
\end{array}$ & $1998-2010$ & ---- & --- & $\begin{array}{l}\text { Yapılan çalışma neticesinde Türkiye'de yatırım } \\
\text { harcamalarının kıyaslanan ülkelere nazaran yeterli } \\
\text { düzeyde olmadığı, yapılan harcamaların ise genellikle } \\
\text { tek seferlik yatırım olduğu ve devamlılığının } \\
\text { olmadığı sonucuna ulaşılmıştır. }\end{array}$ \\
\hline $\begin{array}{l}\text { Apergis and } \\
\text { Sorros (2014) }\end{array}$ & $\mathrm{ABD}$ & $1990-2011$ & $\begin{array}{l}\text { Panel } \\
\text { Cointegration } \\
\text { Test }\end{array}$ & $\begin{array}{l}\text { Aktif Karlılık } \\
\text { (ROA), } \\
\text { Özkaynak } \\
\text { Karlılığı (ROE), } \\
\text { Ar-Ge } \\
\text { Harcamaları } \\
\end{array}$ & $\begin{array}{l}\text { Yapılan analiz sonucunda, yenilenebilir enerji üreten } \\
\text { şirketler grubunda, Ar-Ge harcamalarının karlılık } \\
\text { üzerinde güçlü bir etkisi tespit edilmiştir. Bu grup } \\
\text { şirketlerdeki Ar-Ge harcamaları, satıllan yenilenebilir } \\
\text { enerjiye daha fazla katma değer sağlamıştır. }\end{array}$ \\
\hline $\begin{array}{l}\text { Kocamı̈s ve } \\
\text { Güngör } \\
\text { (2014) }\end{array}$ & Türkiye & $2009-2013$ & $\begin{array}{l}\text { Regression, } \\
\text { Korelason }\end{array}$ & $\begin{array}{l}\text { Ar-Ge, } \\
\text { Dönem net K/Z, } \\
\text { Faaliyet K/Z, } \\
\text { FAVÖK }\end{array}$ & $\begin{array}{l}\text { Yapılan analiz neticesinde } \mathrm{Ar}-\mathrm{Ge} \text { harcamaları ile } \\
\text { Dönem net } \mathrm{K} / \mathrm{Z} \text {, Faaliyet } \mathrm{K} / \mathrm{Z} \text {, FAVÖK arasında } \\
\text { güçlü bir ilişki olduğu tespit edilmiştir. İlişkinin yönü } \\
\text { ise pozitiftir. }\end{array}$ \\
\hline $\begin{array}{l}\text { Shuddhasattwa } \\
\text { vd. (2016) }\end{array}$ & $\begin{array}{l}\text { Çin, } \\
\text { ABD }\end{array}$ & $2009-2013$ & $\begin{array}{l}\text { Panel } \\
\text { Nedensellik }\end{array}$ & $\begin{array}{l}\text { Net Satışlar, } \\
\text { Brüt Kar, } \\
\text { Ar-Ge } \\
\text { Harcamaları, } \\
\text { Firma Yaşı }\end{array}$ & $\begin{array}{l}\text { ABD'li maden firmalarında Ar-Ge'nin satışları ve karı } \\
\text { artırdı̆̆ ancak, Ar-Ge'nin Çinli firmaların kar ve } \\
\text { satışları üzerinde tersi yönde etkisi bulunmuştur. Bu } \\
\text { iki ülke için farklı sonuçların Çin ve ABD'deki } \\
\text { madencilik firmalarının yaşlarındaki farklılıklardan } \\
\text { kaynaklandığı da tespit edilmiştir. Ar-Ge'ye yapılan } \\
\text { yatırımın kar üzerindeki olumlu etkisinin } 37 \text { yıl } \\
\text { olduğu ve Ar-Ge'nin satış üzerinde olumlu bir etkiye } \\
\text { sahip olduğu eşik değerinin } 22 \text { yıl olduğu sonucuna } \\
\text { varılmıştır. }\end{array}$ \\
\hline
\end{tabular}




\begin{tabular}{|c|c|c|c|c|c|}
\hline $\begin{array}{l}\text { Amoroso vd. } \\
\text { (2016) }\end{array}$ & $\begin{array}{l}\text { Euro } \\
\text { Ülkeleri }\end{array}$ & 2004-2012 & $\begin{array}{l}\text { Panel } \\
\text { Nedensellik }\end{array}$ & $\begin{array}{l}\text { Net Satışlar, } \\
\text { Karlılık, Sermaye, } \\
\text { İşçi Sayısı, } \\
\text { Pazar Payı }\end{array}$ & $\begin{array}{l}\text { Riskli kar maksimizasyon senaryosu (Knightian } \\
\text { teorisi) kullanılarak risk ve belirsizliğin kar } \\
\text { üzerindeki etkisinin modellenmesi amaçlanmışıtır. } \\
\text { Sonuçta belirsizlik ve türbülansın yüksek olduğu } \\
\text { dönemlerde Ar-Ge yatırımının öneminin ortaya } \\
\text { çıtı̆̆g belirtilmiştir. Bu bağlamda, Ar-Ge yatırımları } \\
\text { belirsizliğin yarattığı risklerin önlenmesinde katk1 } \\
\text { sağladığı sonucuna ulaşılmıştır.. }\end{array}$ \\
\hline $\begin{array}{l}\text { Sanghoon } \\
\text { (2018) }\end{array}$ & Kore & $1990-2012$ & $\begin{array}{l}\text { Panel } \\
\text { Liquidity } \\
\text { Models }\end{array}$ & $\begin{array}{l}\text { Ar-Ge } \\
\text { Harcamaları, } \\
\text { Büyüme ve } \\
\text { Karlılık }\end{array}$ & $\begin{array}{l}\text { Yapılan çalışma sonucunda kârın büyüme üzerindeki } \\
\text { olumsuz etkisi tespit edilmiş, bu etkinin, yetkili } \\
\text { yöneticilerin yüksek kâr düzeylerini korumaya } \\
\text { çalışmalarından kaynaklandığı sonucuna ulaşılmıştır } \\
\text { Krizden bu yana, Kore'de uygulanmakta olan } \\
\text { ekonomi çapında reformların, büyüme pahasına kâr } \\
\text { hedeflerine odaklanmasına yol açtığı sunucuna } \\
\text { ulaşılmışıtır. } \\
\text { Ampirik analiz, büyümenin tüm örnek dönem için } \\
\text { Ar-Ge yatırımı üzerindeki kar ve nakit akış1 } \\
\text { üzerindeki önemsiz etkilerini rapor etmektedir. }\end{array}$ \\
\hline $\begin{array}{l}\text { İlarslan ve } \\
\text { Biyıklı (2017) }\end{array}$ & Türkiye & 1994-2016 & $\begin{array}{l}\text { Almon } \\
\text { Gecikme } \\
\text { Modeli }\end{array}$ & $\begin{array}{l}\text { Brüt Kar, } \\
\text { Ar-Ge } \\
\text { Harcamaları }\end{array}$ & $\begin{array}{l}\text { Almon Modeli sonuçlarına göre, brüt kar marinının } \\
\text { geçmiş } 6 \text { yıldaki Ar-Ge harcamaları yoğunluğundan } \\
\text { pozitif olarak etkilendiği belirlenmiştir. Ayrıca Ar-Ge } \\
\text { harcamalarının brüt kar üzerindeki etkisinin cari yıllda } \\
\text { geçmiş yıllara göre daha büyük olduğu görülmüștür. }\end{array}$ \\
\hline
\end{tabular}

\section{BULGULAR VE SONUÇ}

\subsection{Panel Birim Kök Testleri}

Yatay kesit gözlemleriyle oluşturulan panel veriler, zaman serisinin özelliklerini ve taşıdığ1 sorunları da bünyesinde taşır. Eğer verilerde birim kökün varlığı tespit edilirse, sahte regresyon sorunu panel veri analizinde de ortaya çıkar. Eşbütünleşme testine geçmeden önce bu sorunun giderilmesi gerekir. Bunun için bu çalışmada Im vd. tarafından 2003'de geliştirilen Panel Unit Root testleri uygulanmıştır. Geliştirilen denklem @'nun her bir yatay kesit için değiştiğini var sayar ve şu şekilde ifade edilir;

$\Delta y_{i t}=\mu_{i}+\theta_{t}+\delta_{i} t+\rho_{i} y_{i t-1}+\sum_{j=i}^{k} \alpha_{j} \Delta y_{i t-j}+e_{i t}$

Im; Pesaran; Shin (2003) testinde sıfır ve alternatif hipotez sınamaları aşağıdaki gibi tanımlamıştır:

$H_{0}: \rho_{i}=0$ bütün yatay kesitler için $(i=1,2, \ldots, N)$

$H_{1}: \rho_{i}<0$ en az bir yatay kesit için $\left(i=N_{1}+1, \ldots, N\right)$

Sıfır hipotezi yatay kesitlerin her birinin birim kök içerdiğini yani durağan olmadığını, alternatif hipotez paneldeki yatay kesitlerin bir veya bir kısmının birim kök içermediğini (durağan olduğunu) ifade etmektedir (Asteriou ve Hall 2007: 367).

Araştırma Geliştirme değişkeni için panel ünit root testi; Ar-Ge verisinin \%1, \%5 ve \%10 anlamlılık düzeylerinde $H_{0}{ }^{\prime}$ ın kabul edildiğini, yani durağan olmadığını göstermektedir. $\mathrm{Bu}$ nedenle, veriler için birincil derece farkları alınarak tekrar teste tabi tutulmuş ve sonuçta yapılan tüm test tipleri için Araştırma ve Geliştirme değişkeni için birinci farkta $H_{0}$ reddedilmiş, yani verilerin durağan olduğu sonucuna ulaşılmıştır. 
Tablo 3. Panel Birim Kök Testleri Sonuçları (Düzeyde ve 1. Farklarda) Ar-Ge (R\&D) Harcamaları

\begin{tabular}{lcccc}
\hline & R\&D & Prob. & $\Delta$ R\&D & Prob. \\
\hline Levin, Lin, Chu & 3,47403 & 0,9997 & $-12,4803^{*}$ & 0,0001 \\
\hline Im, Pesaran, Shin W-stat & 6,97917 & 1,000 & $-6,66918^{*}$ & 0,0001 \\
\hline Fisher-ADF square & 56,4932 & 0,5315 & $235,122^{*}$ & 0,0001 \\
\hline Fisher-PP square & 41,0653 & 0,9549 & $413,853^{*}$ & 0,0001 \\
\hline
\end{tabular}

Not: $\Delta$ değişkenlerin birincil farkları, $* \% 1$ anlamlılık düzeyini ifade etmektedir. (Nerwew-West automatic bandwindth selecton and bartlett kernel, Lag Length Schwarz info Criterion)

Kar değişkeni için panel ünit root testi göstermektedir ki; Ar-Ge verisi düzeyde \%1, \%5 ve $\% 10$ anlam düzeylerinde $H_{0}$ kabul yani durağan değildir. Bu nedenle, veriler için birincil derece farkları alınarak tekrar teste tabi tutulmuş ve sonuçta yapılan tüm test tipleri için kar değişkeni için birinci farkta $H_{0}$ 'ın reddedilmesi gerektiği, yani verilerin durağan olduğu sonucuna ulaşılmıştır.

Tablo 4. Panel Birim Kök Testleri Sonuçları (Düzeyde ve 1. Farklarda) Kar Rakamları

\begin{tabular}{lcccc}
\hline & Kar & Prob. & $\Delta$ Kar & Prob. \\
\hline Levin, Lin, Chu & 11,4787 & 1,00 & $-4,09343^{*}$ & 0,0001 \\
\hline Im, Pesaran, Shin W-stat & 15,1760 & 1,00 & $-2,59343^{*}$ & 0,0048 \\
\hline Fisher-ADF square & 4,41942 & 1,00 & $112,010^{*}$ & 0,0001 \\
\hline Fisher-PP square & 4,79223 & 1,00 & $215,735^{*}$ & 0,0001 \\
\hline
\end{tabular}

Not: $\Delta$ değişkenlerin birincil farkları, * \%1 anlamlılık düzeyini ifade etmektedir. (Nerwew-West automatic bandwindth selecton and bartlett kernel, Lag Length Schwarz info Criterion)

Tablo 3 ve 4 incelendiğinde Araştırma ve Geliştirme verisi ile kar verisinin düzeyde yapılan birim kök test sonucunda birim kök taşıdıkları ve durağan olmadıkları birincil farkları alınarak teste tutulduklarında, birincil derece fark durağan seriler olduğu tespit edilen her iki seri için regresyon denklemi kurulup eşbütünleşmenin varlığg test edilebilir.

\subsection{Pedroni Cointegration Test Sonuçlanı}

Ar-Ge ve kar serileri aynı derecede fark durağan serilerdir. Bu serilerin aralarındaki uzun dönem eşbütünleşmenin varlığını tespit edebilmek için ikinci aşama olarak Pedroni Cointegration testi kullanılmıştır. Pedroni tarafindan 1997, 1999, 2000 ve 2004 yıllarında eş bütünleşme analizinde heterojenliğe imkan veren test önerileri ortaya atılmıştır. Pedroni testleri; birden fazla açıklayıcı değişkene (regressor) izin vermesi, eşbütünleşme vektörünün panelin farklı kısımları boyunca çeşitlenmesinin yanında kesit birimleri boyunca hataların heterojenliğine izin veren özelliğe sahiptir.

Paneldeki kesit içi (within) ve kesitler arası (between) etkilerini kapsayabilmesi için yedi farklı eşbütünleşme testi sunulmuş ve bu testler iki farklı kategoriye ayrılmıştır. İlk kategori "within" boyutunda havuzlanmış dört testi içermektedir. İkinci kategori ise "between" boyutunda diğer üç testi içermektedir (Asteriou ve Hall, 2007: 374). "Birinci kategori içindeki dört testten ilk üçü parametrik olmayan testlerdir. İlk test varyans oranı tipinde bir istatistiktir. İkincisi Phillips-Peron (PP) (rho) istatistiğine, üçüncü istatistik de PP (t) istatistiğine benzemektedir. Dördüncü istatistik ise Augmented Dickey Fuller (ADF) (t) 
istatistiğine benzer parametrik bir istatistiktir. İkinci kategoride üç testten ilki PP (rho) istatistiği ile benzer iken, diğer ikisi PP ( $t$ ) ve ADF ( $t$ ) istatistiklerine benzemektedir (Gülmez ve Yardımcioğlu, 2012:346).

Test sonuçlarına göre, Ar-Ge harcamaları ve kar rakamları arasında uzun dönemli ilişkiyi araştıran Pedroni test sonuçları ve grup istatistiklerinden yedi testin beş tanesi, değişkenler arasında uzun dönem eşbütünleşme ilişkisinin varlığını ortaya koymakta, yalnızca bir tanesi ilişkinin varlığını reddetmektedir. Bu bağlamda elde edilen sonuçların literatürü destekler nitelikte (Shuddhasattwa vd. (2016), Apergis ve Sorros (2014), Gülmez ve Yardımcıoğlu (2012), Francesco ve Mario (2010), İlarslan ve Bıyıklı (2017)) olduğu görülmektedir.

Tablo 5. Panel Pedroni Eşbütünleşme Test Sonuçları

\begin{tabular}{|c|c|c|c|c|}
\hline \multicolumn{5}{|c|}{ Alternative hypothesis: common AR coefs. (within-dimension) } \\
\hline & Statistic & Prob & $\begin{array}{c}\text { Weighted } \\
\text { Statistic }\end{array}$ & Prob. \\
\hline Panel v-Statistic & $3.054712^{*}$ & 0.0010 & -0.091649 & 0.5365 \\
\hline Panel rho-Statistic & $-2.656084^{*}$ & 0.0040 & $-1.594544^{* * *}$ & 0.0554 \\
\hline Panel PP-Statistic & $-2.125949^{* *}$ & 0.0168 & $-1.453723^{* * *}$ & 0.0730 \\
\hline Panel ADF-Statistic & -0.446179 & 0.3277 & -0.515890 & 0.3030 \\
\hline \multicolumn{5}{|c|}{ Alternative hypothesis: individual AR coefs. (between-dimension) } \\
\hline & Statistic & \multicolumn{2}{|c|}{ Prob } & \\
\hline Group rho-Statistic & -0.460213 & \multicolumn{2}{|c|}{0.3227} & \\
\hline Group PP-Statistic & $-2.424562^{*}$ & \multicolumn{2}{|c|}{0.0077} & \\
\hline Group ADF-Statistic & $-1.344415^{* * *}$ & \multicolumn{2}{|c|}{0.0894} & \\
\hline
\end{tabular}

\subsection{DOLS ve FMOLS Test Sonuçları}

Pedroni $(2000,2001)$ tarafından geliştirilen panel DOLS (Dynamic Ordinary Least Square) ve FMOLS (Full Modified Ordinary Least Square) tahmincileri ampirik analizlerde yaygın olarak kullanılan yöntemlerdir. Panel DOLS ve FMOLS tahmincileri bağımsız değişken(ler) ve hata terimi arasındaki içsellik ve hata terimlerindeki kendine bağlı problemlerinin ortadan kaldırılmasında panel EKK (En Küçük Kareler) tahmincisine kıyasla daha etkin oldukları için özellikle tercih edilmektedir (Nazlığlu, 2010: 110).

Ar-Ge harcamalarının kar üzerine etkisini test eden Panel DOLS ve Panel FMOLS test sonuçları Tablo 6'da yer almaktadır. Ar-Ge harcamalarının kar üzerine etkisini test eden Panel DOLS test sonuçlarına göre değişkenler arasında katsayı pozitif ve istatistiki açıdan \%5 düzeyde anlamlıdır. Esneklik katsayısı \%3,4' dür. Yani Ar-Ge harcamalarına yapılacak olan 1 birimlik bir artış, kar üzerinde 3,4 birimlik bir artışa sebep olmaktadır.

Ar-Ge harcamalarının kar üzerine etkisini test eden Panel FMOLS test sonuçlarına göre ise, değişkenler arasında katsayı pozitif ve istatistiki açıdan \%1 düzeyde anlamlıdır. Esneklik katsayısı \%3,8'dir. Yani Ar-Ge harcamalarına yapılacak olan bir birimlik bir artış, kar üzerinde 3,8 birimlik bir artışa sebep olmaktadır. 
Tablo 6. DOLS ve FMOLS Test Sonuçları

\begin{tabular}{llllll}
\hline \multirow{2}{*}{ DOLS } & Değişken & Katsay1 & Std. Error & t-Statistic & Prob. \\
\cline { 2 - 6 } & ARGE & 3.413936 & 1.118439 & 3.052410 & 0.0023 \\
\hline \multirow{2}{*}{ FMOLS } & Değişken & Katsay1 & Std. Error & t-Statistic & Prob. \\
\cline { 2 - 6 } & ARGE & 3.840683 & 0.964098 & 3.983704 & 0.0001 \\
\hline
\end{tabular}

Not: Gecikme uzunluğu seçiminde AIC, Schwarz, Hannan-Quinn (Fixed) temel alınmış (max lag of 3), Kermel metodu kullanılmış (Bartlett), Bandwith genişliği Newey-West yöntemi ile belirlenmiştir.

\section{SONUÇ}

Dördüncü Endüstri Devriminin yaşandığı günümüzde firmalar arası rekabet uluslararası düzeyde gerçekleşmektedir. Rekabet avantajı sağlamak için firmaların öncelikle araştırma ve geliştirme faaliyetlerine yatırım yapması gerekmektedir. Ar-Ge faaliyetlerine yapılan yatırımlar kısa dönemde olmasa da, uzun dönemde firmanın karlılığını artırarak rekabet avantajı sağlamaktadır. Bu çerçevede ülkemizde Ar-Ge yatırımı yapan firmaların Ar-Ge harcamalarının karlılığa etki düzeyi belirlenmeye çalışılmıştır.

Çalışmada BİST-100 endeksinde yer alan firmalar için 1990-2017 yıllarını kapsayan dönemde düzenli olarak Ar-Ge harcaması yapan firmaların Ar-Ge harcamaları ile kar rakamları arasında eşbütünleşme ilişkinin varlığı test edilmeye çalışılmıştır. Söz konusu dönem aralığında Ar-Ge yatırımları süreklilik arzeden 29 firma veri setine dahil edilmiştir. Bu firmaların büyük bir kısmı otomotiv, beyaz eşya, enerji gibi teknoloji yoğun sektörlerde yer almaktadır.

Çalışmanın analiz kısmında, serilerin birincil farklarının (I(1)) durağan olduğu olduğu tespit edilmiştir. Daha sonra, durağanlık şartı sağlanan veriler için eşbütünleşme testi yapılmış, değişkenlerin uzun dönemde eşbütünleşme ilişkisi Pedroni Eşbütünleşme ile analiz edilmiştir. Sonuçta değişkenler için uzun vadede pozitif ve anlamlı eşbütünleşme ilişkisinin varlığı tespit edilmiştir. Bu ilişkinin katsayıları Panel DOLS ve FMOLS testleri ile incelenmiş, DOLS testi için, Ar-Ge harcamaları ile kar rakamlarının esnekliği \%3,4 bulunmuştur. Yani Ar-Ge harcamalarında \%1'lik bir artış kar rakamları üzerinde \%3,4'lük bir artış sağlamaktadır. FMOLS testi için ise söz konusu değişkenler için esneklik kat sayısı \%3,8 bulunmuştur. Yani Ar-Ge harcamalarında \%1'lik bir artış kar rakamlarında \%3,8'lik bir artışa neden olmaktadir.

Tüm bu sonuçlar birlikte değerlendirildiğinde BİST-100'de işlem gören örneklemdeki firmaların yapmış oldukları Ar-Ge harcamalarının, bu firmaların kar rakamları üzerinde uzun dönemde literatürü destekler nitelikte eşbütünleşik olduğu, yani uzun dönemde birlikte hareket ettikleri ve hareket yönünün pozitif yönlü olduğu söylenebilmektedir. Ancak, ülkemizde halka açık firmalarda bile Ar-Ge faaliyetlerine istikrarlı bir şekilde sadece 29 firmanın yatırım yapıyor olması, ülke sıralamasında Ar-Ge yatırımlarında neden geri kaldığımızı göstermektedir. Oysa ülkelerin gelişmişlik düzeyi ile Ar-Ge harcamaları arasında parelel bir durum sözkonusudur. Ülkemizdeki firmaların uluslararası düzeyde rekabet edebilmesi için, aynı zamanda ülke olarak gelişmiş ülkeler sıralamasında üst sıralara çıkabilmek için Ar-Ge yatırımlarının artırılması gerekmektedir. 


\section{KAYNAKÇA}

Aksoylu, S., Boztosun, D., Altınışık, F., \& Baraz, E. H. (2017). Determination of the Relationship between Operating Cycle Risks and Other Risks: An Application on the Bist Textile Index. Journal of Accounting \& Finance, July 2017 Special Issue, 65-79.

Adaçay, F. R. (2007). Bilgi Ekonomisine İlişkin Temel Göstergeler Açısından Avrupa Birliği ve Türkiye'nin Karşılaştırılması. Dumlupınar Üniversitesi Sosyal Bilimler Dergisi, Sayı: 19, 185-204.

Aghion, P., \& Howitt, P. (1992). A Model of Growth Through Creative Destruction. Econometrica, 60(2), 323-351.

Aksoylu, S., Boztosun, D., Altınışık, F., \& Baraz, E. H. (2017). Determination of The Relationship Between Operating Cycle Risks and Other Risks: An Application on The Bist Textile Index. Muhasebe ve Finansman Dergisi, Temmuz, 65-80.

Altın, O. ve Kaya, A. (2009). Türkiye'de Ar-Ge Harcamaları ve Ekonomik Büyüme Arasındaki Nedensel İlişkinin Analizi. Ege Akademik Bakış, 9(1), 251-259. DOI: 10.21121/eab.2009119742.

Altıntaş, H. ve Mercan, M. (2015). Ar-Ge Harcamaları ve Ekonomik Büyüme İlişkisi: OECD Ülkeleri Üzerine Yatay Kesit Bağımlılığı Altında Panel Eşbütünleşme Analizi. Ankara Üniversitesi SBF Dergisi, 70(2), 345-376.

Amoroso, S., Moncada-Paternò-Castello, P., \& Vezzani, A. (2017). R\&D Profitability: The Role of Risk and Knightian Uncertainty. Small Business Economics, 48(2), 331-343.

Apergis, N., \& Sorros, J. (2014). The Role of R\&D Expenses for Profitability: Evidence from U.S. Fossil and Renewable Energy Firms. International Journal of Economics and Finance, 6(3), 8-15.

Asteriou, D., \& Hall, S. G. (2007). A Modern Approach Using Eviews and Microfit. Revised Edition, Palgrave McMillan, New York.

Baltagi, B. H. (2011). Econometrics. Fifth Edition, Springer, New York.

Çelik, Ş. ve Özbay N. (2015). Almon Gecikme Modeli ile Domates Üretiminde Üretim-Fiyat İlişkisinin Analizi: Türkiye Örneği. Türk Tarım ve Doğa Bilimleri Dergisi, 2(2): 207-213.

Eurostat, (2016).

http://ec.europa.eu/eurostat/tgm/table.do?tab=table\&init=1\&language=en\&pcode=t20

20 20\&plugin $=1$ (Erişim Tarihi: 07.04.2018)

Francesco, B., \& Mario, P. (2010). Profits, R\&D and Innovation: a Model and a Test. JRC Working Papers on Corporate RED and Innovation 2010-05, Joint Research Centre (Seville site).

Graham, K. M. (1989). R\&D Expenditures and Profit Growth. Research Technology Management, 32(3), 20-23.

Grossman, G. M., \& Helpman, E. (1991). Trade, Knowledge Spillovers, and Growth. European Economic Review, 35(2-3), 517-526. 
Gülmez, A. ve Yardımcıoğlu, F. (2012). OECD Ülkelerinde Ar-Ge Harcamaları ve Ekonomik Büyüme İlişkisi: Panel Eşbütünleşme ve Panel Nedensellik Analizi. Maliye Dergisi, Sayı 163, 335-353.

https://biruni.tuik.gov.tr/medas/?kn=124\&locale=tr (Erişim Tarihi: 03.05.2018)

http://stats.oecd.org/glossary/detail.asp?ID=3111 (Erişim Tarihi: 15.04.2018)

https://data.oecd.org/rd/gross-domestic-spending-on-r-d.htm\#indicator-chart (Erişim Tarihi: 15.04.2018)

Hu, A. G., \& Jefferson, G. H. (2004). Returns to Research and Development in Chinese Industry: Evidence From State-Owned Enterprises in Beijing. China Economic Review, 15(1), 86-107.

İlarslan, K. ve Bıyıklı, F. (2017). Araştırma-Geliştirme Harcamalarının İşletmelerin Finansal Performansına Etkisinin Ekonometrik Analizi: İlaç Sektöründen Bir Uygulama. ASEAD, 5(3), 122-137.

Im, K. S., Pesaran, M. H., \& Shin, Y. (2003). Testing For Unit Roots in Heterogeneous Panels. Journal of Econometrics, 115(1), 53-74.

Kabakçı, A. (2012). Opsiyon Duyarlılık Parametrelerinin İncelenmesine Yönelik Bir Araştırma. Dokuz Eylül Üniversitesi, Sosyal Bilimler Enstitüsü Dergisi, 14(2), 87-103.

Karğın, M. (2008). Hisse Senedi Piyasalarında Eşbütünleşme Analizi. Finans Politik $\mathcal{E}$ Ekonomik Yorumlar Dergisi, 45(525), 85-96.

Kocamış, T. ve Güngör, A. (2014), Türkiye'de Ar-Ge Harcamaları ve Teknoloji Sektöründe Ar-Ge Giderlerinin Kârlılık Üzerine Etkisi: Borsa İstanbul Uygulaması. Maliye Dergisi, Sayı 166, 127-138.

Korkmaz, S. (2010). Türkiye' de Ar-Ge Yatırımları ve Ekonomik Büyüme Arasındaki İlişkinin VAR Modeli İle Analizi. Journal of Yaşar University, 20(5), 3320-3330.

Korkut, N. ve Sabah, B. (2016). Çokuluslu Şirketlerin Ar-Ge Harcamalarında Sektörel Eğilimler Ve Teknolojik Yeniliklerde Öncü Şirketler. Marmara Üniversitesi Sosyal Bilimler Enstitüsü, Yayınlanmamış Yüksek Lisans Tezi.

Levin, A., Lin, C. F., \& Chu, C. S. J. (2002). Unit Root Tests in Panel Data: Asymptotic and Finite-Sample Properties. Journal of Econometrics, 108(1), 1-24.

Nazlıŏlu, Ş. (2010). Makro İktisat Politikalarının Tarım Sektörü Üzerindeki Etkileri: Gelişmiş ve Gelişmekte Olan Ülkeler İçin Bir Karşılaştırma. Erciyes Üniversitesi Sosyal Bilimler Enstitüsü, Yayınlanmamış Doktora Tezi.

Nicholas, A., \& John, S. (2014). The Role of R\&D Expenses for Profitability: Evidence from U.S. Fossil and Renewable Energy Firms. International Journal of Economics and Finance, 6(3), 8-15.

Pedroni, P. (2004). Panel Cointegration: Asymptotic and Finite Sample Properties of Pooled Time Series Tests with an Application to the PPP Hypothesis. Econometric Theory, 20(3), 597-625. 
Romer, P. M. (1990). Endogenous Technological Change. Journal of Political Economy, 98(5, Part 2), 71-102.

Sanghoon, L. (2018). Growth, Profits and R\&D Investment. Economic Research-Ekonomska Istraživanja, 31(1), 607-625.

Shuddhasattwa, R., Ruhul, S., \& Russell, S. (2016). The Moderating Role of Firm Age in the Relationship between R\&D Expenditure and Financial Performance: Evidence from Chinese and US Mining Firms. Economic Modelling, 56, 122-132.

Ünal, T. ve Seçilmiş, N. (2013), Ar-Ge Göstergeleri Açısından Türkiye ve Gelişmiş Ülkelerle Kıyaslaması. İşletme ve İktisat Çalışmaları Dergisi, 1(1), 12-25. 